\title{
UPAYA MEWUJUDKAN PEMBANGUNAN BERKELANJUTAN MELALUI PENDIDIKAN LINGKUNGAN
}

\author{
Oleh: Iwan Setiawan*)
}

\begin{abstract}
ABSTRAK
Kerusakan lingkungan yang terjadi di berbagai kawasan dunia saat ini telah sampai pada taraf yang mengkhawatirkan. Berbagai indikator lingkungan menunjukkan hal tersebut, sehingga berbagai pihak telah dan sedang berupaya keras untuk mengatasinya. Upaya-upaya tersebut, tidak jarang masih bersifat lokal atau sporadis dan jangka pendek, sehingga kerusakan lingkungan terus terjadi. Solusi jangka panjang tengah di perjuangkan oleh berbagai lembaga baik di dunia maupun Indonesia yaitu dengan menyiapkan generasi yang akan datang melalui pendidikan lingkungan. Di tingkat dunia, organisasi-organisasi di bawah naungan PBB terus berupaya menggalang kerjasasama antar negara dalam membangun kesadaran lingkungan. Berbagai konferensi telah diselenggarakan dan sejumlah konvensi telah dihasilkan yang sangat bermanfaat sebagai dasar atau kerangka dalam merancang program di tiap negara. Indonesia sebagai salah satu negara yang memiliki posisi penting dalam tatanan lingkungan dunia juga terus mengikuti perkembangan tersebut. Kerusakan lingkungan yang terjadi di negara ini tidak bisa hanya diatasi sendiri tetapi memerlukan kerjasama dengan negara lain. Kementrian Negara Lingkungan hidup juga menjalin kerjasama dengan departemen lainnya untuk mengatasi permsalahan yang ada. Kerjasama penting telah dilakukan dengan Depdiknas dan Departemen Agama dengan merancang progam pendidikan lingkungan hidup bagi generasi penerus.
\end{abstract}

Kata kunci: Pembangunan berkelanjutan, Pendidikan lingkungan.

\section{Pendahuluan}

Pendidikan lingkungan yang akhir-akhir ini menjadi bahan pembicaraan di banyak media merupakan sebuah cermin dari kegalauan akan pemasalahan lingkungan yang semakin mengkhawatirkan. Kegalauan tersebut sangat logis ketika permasalahan lingkungan sudah sampai pada taraf mengganggu, bahkan mengancam jiwa manusia. Banyak orang yang sudah merasakan dampak langsung dari kerusakan lingkungan yang terjadi seperti banjir, kemarau, berjangkitnya bibit penyakit dan lain-lain.

*) Iwan Setiawan, S.Pd., M.Si., adalah dosen Jurusan Pendidikan Geografi FPIPS UPI. 
Walaupun perhatian terhadap masalah lingkungan mulai muncul tetapi tidak lantas begitu saja permasalahan tersebut selesai. Permasalahan lingkungan terus muncul dan berkembang, bahkan cenderung bergerak ke arah yang semakin mengkhawatirkan. Upaya untuk mencegah dan mengatasi masalah lingkungan kalah cepat dibandingkan dengan tindakantidakan yang menimbulkan kerusakan lingkungan. Akibatnya masalah lingkungan terus terjadi dan berkembang makin tak terkendali.

Hal tersebut mengisyaratkan bahwa upaya pencegahan lingkungan tidak dapat dilaksanakan dalam jangka pendek dan temporal serta sporadis. Dalam jangka panjang perlu dilakukan perencanaan yang matang, terutama menyiapkan generasi penerus untuk lebih peduli terhadap lingkungan.

Upaya-upaya untuk membina generasi penerus dengan pendidikan lingkungan sebenarnya telah cukup lama diperjuangkan. Pada level internasional berbagai lembaga dunia, khususnya di bawah naungan PBB terus menjalin kerjasama seluruh negara untuk menyadarkan warga dunia akan bahaya yang mengancam kehidupan di dunia yang sudah pada taraf mengkhawatirkan. Di Indonesia, upaya memupuk kepedulian terhadap lingkungan juga semakin mendapat perhatian walaupun masih banyak kelemahan dan tantangan yang cukup besar. Tulisan ini akan membahas upaya-upaya yang telah dilakukan masyarakat internasional maupun Indonesia dalam upaya mewujudkan pembangunan berkelanjutan, khususya melalui pendidikan lingkungan.

\section{Upaya internasional}

Upaya untuk mewujudkan masyarakat dunia yang peduli terhadap lingkungan hidup telah cukup lama dilakukan. Sutrisno (2005) membagi upaya-upaya tersebut menjadi lima tahap atau periode. Pada periode sebelum tahun 1940 terdapat sejumlah kesepakatan yang dilakukan oleh masyarakat internasional berupa Convention for Protection of Useful Birds to Agriculture (1902), Treaty of Preservations of Fur Seals (Wahington 1911), Convention Regulation of Whaling (1931), dan Convention on Nature Protection and Wildlife Preservation in the Western Hemisphere (Washington 1940).

Pada periode 1940 sampai dengan 1972 tercatat hampir 60 perjanjian internasional yang berisi perlindungan beberapa komponen lingkungan hidup yang dianggap bernilai bagi manusia. Organisasi di bawah PBB berperan aktif dalam mengangkat isu lingkungan seperti WHO, WMO, ICAO, IAEA, FAO, UNESCO, OECD, IMO, ILO dan lain-lain. Pada tahun 1968 dan 1969 PBB mengesahkan resolusi guna menyelenggarakan The United Nations Conference on Humant Environment. Konferensinya itu sendiri baru terwujud pada tahun 1972 yang diselenggarakan di Stockholm atau dikenal dengan konferensi Stockholm 1972.

Pada periode 1972-1992 atau setelah konferensi Stockholm, PBB membentuk United Nation Environment Programme (UNEP) dan Dana Lingkungan (Environment Fund). Pada periode ini dilakukan penanganan masalah-masalah lingkungan yang konvensional seperti pelestarian flora dan fauna langka, polusi air dan udara, perlindungan habitat dan lain-lain. Beberapa konvensi telah dihasilkan pada periode ini diantaranya adalah 
konvensi Vienna untuk perlindungan lapisan ozone (1985), Protokol Montreal tentang substansi yang merusak lapisan ozon (1987), Konvensi Biodiversity (1992) dan lain-lain. Pada periode ini pula dibentuk World Commision on Environment and Development/Brundland Commission (WCED) yang melakukan pendekatan integral dalam menanggapi permasalahan lingkungan hidup yang kemudian berkembang menjadi konsep Pembangunan Berkelanjutan. Laporannya diberi judul Masa Depan Kita Bersama (Our Common Future) yang dijadikan dasar dalam persiapan Konferensi Rio De Janeiro di Brazil.

Pada periode 1992-2002 terjadi kemajuan-kemajuan berupa semakin meningkatnya kesadaran negara-negara di dunia tentang pentingnya pembangunan berkelanjutan. Pada tahun 1992 berlangsung Konferensi PBB untuk Lingkungan dan Pembangunan (United Nation Conference on Environment and Development/UNCED) yang menghasilkan Deklarasi Rio (Rio Declaration) dan Agenda 21. Pada periode ini dibentuk Komisi Pembangunan Berkelanjutan (Commision on Sustainable Development/CSD) di bawah ECOSOC. Sejumlah konvensi yang dihasilkan pada periode ini diantaranya adalah Konvensi Rotterdam tentang perdagangan bahan kimia berbahaya dan pestisida (1998) Protokol Kyoto tentang Perubahan Iklim (1998), Protokol Kartagena yang berisi implementasi Konvensi PBB tentang Biodiversity dan lain-lain.

Periode 2002 sampai sekarang telah dilaksanakan KTT Pembangunan Berkelanjutan yang diselenggarakan di Johannesburg Afrika Selatan tahun 2002. KTT ini sebenarnya menindaklanjuti Deklarasi Rio dan Agenda 21 yang dihasilkan pada konferensi Rio dan menjabarkan agenda 21 menjadi Plan of Implementation yang berorientasi aksi dan terukur.

\section{Perjuangan Melalui Jalur Pendidikan}

Masyarakat internasional tidak hanya berupaya melindungi lingkungan melalui berbagai konvensi yang dihasilkannya tetapi juga melalui jalur pendidikan lingkungan. Pada saat masalah lingkungan hidup ramai dibicarakan, secara simultan UNEP, UNESCO dan IEEF (International Environment Education Program) mengadakan beberapa kali pertemuan yang membahas masalah pendidikan lingkungan hidup yaitu di Paris pada tahun 1974, Belgrade pada tahun 1975, Tblisi pada tahun 1987 dan lain-lain. Salah satu hasil dari pertemuan itu adalah dirumuskannya definisi tentang Pendidikan Lingkungan Hidup sebagai berikut:

Environmental Education is the process of recognizing values and clarifying concepts in order to develop skills and attitudes necessary to understand and appreciate the inter-relatedness among men, his culture and his biological surroundings. Environmental education also entails practice in decision making and self-formulation of a code of behavior about issues concerning environmental quality (UNESCO 1983)

Definisi tersebut memberikan arahan yang jelas bahwa pendidikan lingkungan bukan sekedar memberikan pengetahuan tentang lingkungan 
tetapi membentuk keterampilan dan sikap yang baik terhadap lingkungan. Semua itu memerlukan proses pengenalan nilai dan konsep tentang hubungan antara manusia dan lingkungannya.

Upaya mewujudkan pembangunan berkelanjutan memlaui pendidikan semakin jelas setelah dilaksanakan Pertemuan Tingkat Tinggi Pembangunan Berkelanjutan (World Summit on Sustainable Development atau WSSD) tanggal 25 Agustus sampai dengan 4 September 2002 di Johannesburg Afrika Selatan. Pertemuan tersebut membahas antara lain implementasi Agenda 21 yang meliputi rencana program aksi di bidangbidang sosial, ekonomi dan lingkungan hidup.

WSSD juga menghasilkan rekomendasi penting yaitu berupa dokumen Millenium Development Goals (MDGs) yang di dalamnya menekankan bahwa dalam mewujudkan pembangunan berkelanjutan pendidikan merupakan unsur terpenting. MDGs juga menghapus paradigma lama yaitu mengejar kepentingan ekonomi dan sosial melalui pertumbuhan eokonomi tanpa mempertimbangkan aspek lingkungan. Prinsip yang dikembangkan yaitu konsep pembangunan yang mengintegrasikan aspekaspek ekonomi, sosial dan ekologi dalam setiap kegiatan pembangunan. Catatan penting dari MDGs adalah mengamanatkan pada setiap negara untuk mengintegrasikan perspektif pembangunan berkelanjutan ke dalam sistem pendidikan di semua jalur/jenjang pendidikan yang ada.

Menindaklanjuti MDGs, pada Bulan Mei 2003, Komisi Ekonomi PBB untuk Eropa telah melaksanakan konferensi bagi para menteri lingkungan hidup negara-negara Eropa, Canada dan Amerika Serikat di Kiev Ukraina. Hasil dari konferensi tersebut adalah sejumlah rekomendasi yang salah satunya adalah adanya keharusan untuk memperbaiki sistem pendidikan dan mendesain program pembelajaran bagi pembangunan berkelanjutan dengan maksud agar dapat meningkatkan pemahaman semua pihak masyarakat dalam hal bagaimana mempromosikan dan melaksanakan pembangunan yang berkelanjutan. Inti dari konferensi Kiev adalah :

1) Pendidikan untuk pembangunan berkelanjutan adalah isu multisektor yang membahas dimensi ekonomi, lingkungan hidup dan sosial serta mengharapkan adanya suatu pendekatan yang partisipatif dan holistik.

2) Pembelajaran pada setiap level/tingkatan harus terus diupayakan dan perlu menggunakan pemikiran dan refleksi yang kritis sebagai pra syarat untuk tindakan yang nyata bagi pelaksanaan pembangunan berkelanjutan.

3) Pembangunan berkelanjutan perlu terus disampaikan kepada seluruh perancang pendidikan di semua tingkatan, termasuk kursus praktis pendidikan yang berjenjang.

4) Pendidikan adalah proses sepanjang masa yang dapat meliputi pendidikan formal, nonformal dan informal.

5) Tujuan akhir dari pembangunan berkelanjutan adalah untuk meningkatkan kemampuan masyarakat agar dapat melaksanakan perubahan yang positif dan berwawasan lingkungan. Untuk itu, diperlukan adanya proses orientasi dan pendekatan yang partisipatif. 


\section{Perjuangan di Indonesia}

Sebagai salah satu negara yang kaya akan sumberdaya alam, baik hayati maupun non hayati, Indonesia memiliki pandangan yang sama dengan masyarakat internasional tentang pentingnya pendidikan lingkungan bagi generasi saat ini dan terutama generasi penerus. Ketidakberdayaan dalam mengendalikan kerusakan lingkungan semakin menyadarkan semua pihak bahwa pendidikan merupakan solusi jangka panjang yang sangat efektif.

Sebagai wujud dari komitmennya terhadap pendidikan lingkungan, maka pada tanggal 19 Pebruari 2004, Kementrian Negara Lingkungan Hidup bersama sama dengan Departemen Pendidikan Nasional, Departemen Agama dan Departemen Dalam Negeri telah menetapkan kebijakan Pendidikan Lingkungan Hidup (PLH) yang dijadikan dasar atau arahan bagi seluruh Stakeholder/pihak terkait dalam pelaksanaan dan pengembangan pendidikan lingkungan hidup di Indonesia.

Kementrian Negara Lingkungan Hidup juga mengembangkan program adiwiyata yang bertujuan menciptakan kondisi yang baik bagi sekolah untuk menjadi tempat pembelajaran dan penyadaran warga sekolah (guru, murid dan pekerja lainnya), sehingga di kemudian hari warga sekolah tersebut dapat bertanggungjawab dalam upaya-upaya penyelamatan lingkungan dan pembangunan berkelanjutan. Program tersebut telah menghasilkan sekolah-sekolah yang memiliki kepedulian tinggi terhadap lingkungan.

Di Jawa Barat, Badan Pengendalian Lingkungan Hidup Daerah (BPLHD) Jawa Barat mengembangkan Sekolah Berbudaya Lingkungan (SBL). SBL bertujuan untuk menyediakan wahana yang mampu mendukung dan berperan nyata dalam upaya menumbuh-kembangkan generasi penerus dan sumberdaya manusia saat ini yang berbudaya lingkungan, dalam arti sadar dan memahami kondisi lingkungan hidup sekolah dan lingkungan sekitar saat ini sebagai suatu ekosistem, serta mengembangkan cipta, rasa, karsa, dan karya untuk memelihara, memperbaiki, dan meningkatkan kualitas lingkungan hidup saat ini dan yang akan datang.

Baik Adiwiyata maupun SBL sebenarnya tidak hanya sekedar memberikan materi lingkungan pada siswa di kelas. Lebih jauh dari itu, keduanya menekankan pentingnya membudayakan sikap dan perilaku yang peduli terhadap lingkungan dalam baik di sekolah maupun di luar sekolah. Konsep berbudaya lingkungan mengandung makna bahwa kepedulian terhadap lingkungan harus menjadi bagian dari kehidupan sehari-hari warga sekolah. Penghematan energi, air, material, menjadi kebiasaan yang tertanam kuat pada setiap warga sekolah. Begitu pula dengan penataan sekolah, baik bangunan dan lingkungannya yang nyaman menjadi bagian dari SBL. Dalam SBL keterlibatan siswa menjadi fokus karena merekalah yang akan menggantikan generasi saat ini. Aspek proses juga menjadi hal penting dalam SBL, sehingga sekolah yang baik adalah sekolah yang melibatkan siswa secara aktif dalam proses pengelolaan lingkungan sekolah. 


\section{Tantangan yang masih menghadang}

Berbagai masalah lingkungan yang semakin tak terkendali menunjukkan bahwa pendidikan lingkungan belum berhasil membentuk manusia yang peduli terhadap lingkungan. Kegagalan tersebut terjadi karena adanya sejumlah kelemahan dalam pendidikan lingkungan. BPLHD Jawa Barat kegagalan tersebut tidak lepas dari hal-hal berikut:

1) Masih rendahnya partisipasi masyarakat untuk berperan dalam Pendidikan Lingkungan Hidup, karena kurangnya pemahaman terhadap permasalahan pendidikan lingkungan, rendahnya tingkat kemampuan atau keterampilan, dan rendahnya komitmen masyarakat dalam menyelesaikan permasalahan tersebut;

2) pemahaman pelaku pendidikan terhadap pendidikan lingkungan yang masih terbatas menjadi kendala pula. Dalam jalur pendidikan formal, masih ada anggapan bahwa Pendidikan Lingkungan Hidup tidak begitu penting;

3) materi dan metode pelaksanaan Pendidikan Lingkungan Hidup dirasakan belum memadai, dan kurang aplikatif, sehingga pemahaman kelompok sasaran mengenai pelestarian lingkungan hidup menjadi tidak utuh.

4) sarana dan prasarana dalam Pendidikan Lingkungan Hidup belum mendapatkan perhatian yang cukup. Sarana dan prasarana untuk Pendidikan Lingkungan Hidup seringkali disalahartikan sebagai sarana fisik yang berteknologi tinggi sehingga menjadi faktor penghambat tumbuhnya motivasi dalam pelaksanaan Pendidikan Lingkungan Hidup

5) kurangnya kemampuan Pemerintah untuk mengalokasikan dan meningkatkan anggaran pendidikan lingkungan, sehingga pelaksanaan Pendidikan Lingkungan Hidup di berbagai instansi tidak dapat maksimal;

6) lemahnya koordinasi antar instansi terkait dan para pelaku pendidikan menyebabkan kurang berkembangnya Pendidikan Lingkungan Hidup. Hal ini terlihat pada gerakan Pendidikan Lingkungan Hidup (formal dan nonformal/informal) yang masih bersifat sporadis, tidak sinergis dan saling tumpang tindih

Hal senada juga disampaikan oleh Sungkowo (2005) yang mengemukakan bahwa hambatan yang dihadapi dalam pendidikan lingkungan adalah masih adanya permasalahan internal di Ditjen Dikdasmen dan Permasalahan Eksternal di lapangan. Permasalahan internal diantaranya adalah belum adanya konsep PLH yang baku, belum adamya rencana strategi pelaksanaan PLH, sosialisasi internal masih kurang dan lain-lain. Adapun permasalahan yang eksternal adalah:

1) Pola pelatihan belum efektif, kepala sekolah yang telah mendapatkan pelatihan kurang mensosialisasikannya.

2) Metode pengajaran didominasi oleh ceramah.

3) Kurikulum yang sudah ada sangat padat, sehingga sulit mengintegrasikan PLH ke dalamnya.

4) Penegakan hukum di masyarakat masih rendah dan keadaan lingkungan sekolah jauh lebih baik daripada lingkungan di luar. Karena itu pendidikan siswa tidak optimal karena tidak sinkron dengan kondisi di luar. 
5) Tidak ada target yang jelas dalam pelaksanaan.

6) Keterlibatan lembaga yang lain masih rendah.

\section{Penutup}

Walaupun berbagai lembaga di dunia telah berupaya keras untuk mengarasi permasalahan lingkungan namun belum cukup memadai untuk mengatasi permasalahan yang sudah sedemikian berat dan kompleks. Upaya yang lebih besar perlu diarahkan tidak hanya untuk mengatasi permasalahan jangka pendek tetapi juga dalam jangka panjang dengan menyiapkan generasi yang lebih arif dalam memanfaatkan lingkungan. Banyak kendala dan tantangan yang menghadang dan harus segera direspon bersama, sehingga kerjasama antar lembaga mesti dilakukan terus menerus.

\section{Daftar Pustaka}

Badan Pengendalian Lingkungan Hidup Daerah Jawa Barat, 2006. Pedoman Sekolah Berbudaya Lingkungan. Bandung: BPLHD

Hutomo, 2005. Peran Pendidikan Lingkungan Hidup dalam Decade of Education for Sustainable Develpment (DESD). Jakarta: Deputi Bidang Kebijakan dan Kelembagaan Lingkungan Hidup

Sungkowo, 2005. Konsep Pendidikan Lingkungan Hidup pada Jalur Pendidikan Dasar dan Menengah. Jakarta: Dikdasmen

Sutrisno, Tupuk, 2005. Hasil KTT Pembangunan Berkelanjutan di Johannesburg 2002. WATAPRI UNEP

World Commission on Environment and Development, 1988. Hari Depan Kita Bersama. Jakarta: Gramedia. 